\title{
Global Partial Response GvHD
}

National Cancer Institute

\section{Source}

National Cancer Institute. Global Partial Response GVHD. NCI Thesaurus. Code C126723.

A clinician overall severity score that has decreased by 2 or more points on a 0-10 scale. 